\title{
JUDICIALIZAÇÃO DA SAÚDE NO BRASIL: DO CONTEXTO HISTÓRICO ÀS PERSPECTIVAS FUTURAS
}

\author{
Danilo Di Paiva Malheiros Rocha* \\ Adriana Vieira de Castro* \\ Wanessa Oliveira Alves ${ }^{* * * *}$
}

\section{Resumo:}

Analisa o fenômeno da judicialização da saúde no Brasil, aspectos históricos, atuais e perspectivas futuras. Objetiva compreender as causas, o panorama atual e analisar alternativas para sua redução. Utilizou-se revisão integrativa através do método indutivo. Concluiu que o regime militar é a causa da judicialização nos países da América Latina e, caso este panorama permaneça, a saúde pública está fadada ao fracasso. Alternativas são sugeridas, como a autocomposição, instauração de câmaras técnicas, varas especializadas e fortalecimento dos conselhos de saúde a fim de reduzir a incidência ações que, muitas das vezes privilegia o individual em detrimento da coletividade.

Palavras-Chave: Judicialização; Saúde; Causas; SUS; Perspectivas.

\section{JUDICIALIZATION OF HEALTH IN BRAZIL: FROM THE HISTORICAL CONTEXT TO FUTURE PERSPECTIVES}

\begin{abstract}
:
Analyzes the judicialization of health in Brazil, historical, current and future perspectives. Aims to understand the causes, the current situation and analyze alternatives for its reduction. Integrative review and inductive method was used. We concluded that the military regime is the cause of judicialization in the countries of Latin America and, if this scenario remains, Brazilian public health is bound to fail. Alternatives are suggested, such as self-composition, installation of technical chambers, specialized courts and strengthening of health councils in order to reduce the incidence of lawsuits that, many times, privilege the individual to the detriment of the community.
\end{abstract}

Keywords: Judicialization; Health; Causes; SUS; Perspectives

\section{Introdução}

\footnotetext{
* Doutorando no Programa de Pós Graduação em Ciências da Saúde da Universidade Federal de Goiás, Professor na Universidade Estadual de Goiás (UEG-GO) e Advogado. E-mail: Danilo_gestor@yahoo.com.br

*** Doutoranda no Programa de Pós Graduação em Direito Público da Universidade Estácio de Sá, Professora na Pontifícia Universidade Católica de Goiás (PUC-GO) e Oficial de Justiça e Avaliadora do TJ-GO. E-mail: dri.vcastro@ig.com.br

*** Doutoranda no Programa de Pós Graduação em Direito Público da Universidade Estácio de Sá e servidora do TJ-GO. E-mail: alves.wanessa@yahoo.com.br
} 
A saúde pública no Brasil é um tema que desperta interesse em diversos ramos de conhecimento devido à grande demanda da população brasileira desde consultas médicas, medicamentos, vagas de UTI, exames, próteses, até procedimentos cirúrgicos.

$\mathrm{O}$ direito humano à saúde está inserido nos direitos humanos por ser uma decorrência do direito à vida, em 1948, na Declaração Universal de Direitos Humanos (ONU, 1948, art. 25), que assegura:

Toda a pessoa tem direito a um nível de vida suficiente para lhe assegurar e à sua família a saúde e o bem-estar, principalmente quanto à alimentação, ao vestuário, ao alojamento, à assistência médica e ainda quanto aos serviços sociais necessários, o direito à segurança, em caso de desemprego, doença, invalidez, viuvez, velhice ou outros casos de perda dos meios de subsistência em circunstâncias fora de seu controle.

No Brasil, assunto é tratado no ordenamento jurídico brasileiro, mormente na Constituição Federal de 1988 que deve ser acatada por todas as normas infraconstitucionais. Embora o atendimento à saúde seja legalmente previsto, a solução não chegou à casa de quem mais necessita.

A implementação dos direitos sociais fundamentais, sobretudo por ter aplicação imediata como estabelece o parágrafo $1^{\circ}$ do art. $5^{\circ}$, obriga o Estado a atuar de forma positiva, através de políticas públicas. O grande problema das políticas públicas é adentrar na órbita do orçamento público, o qual, como se sabe, não é suficiente para atender toda demanda de uma nação; há escassez de recursos, o que provoca a crise no serviço público.

De acordo com o Ministério da Saúde, dentre os serviços mais utilizados no Sistema Único de Saúde - SUS, prevalecem as consultas médicas, seguidas pela assistência farmacêutica.

Entretanto, as pessoas estão cada vez mais batendo às portas do Poder Judiciário em busca da assistência à saúde. Trata-se do fenômeno da Judicialização da Saúde.

Loiane Prado Verbicaro (2017, p.186), define judicialização como a "expansão dos poderes do Judiciário sobre as políticas legislativas ou executivas do Estado". Há, assim, uma transferência, para o Judiciário, de questões antes afetas tão-somente aos poderes institucional e democraticamente constituídos para tal mister.

Delduque, Marques, Cialini definem a judicialização como: 
fenômeno político-social, no sentido do alargamento das possibilidades de ação junto ao Poder Judiciário, e do aumento exponencial do número de demandas, de caráter individual, interpostas junto a esse poder, que versam sobre questões de saúde" (DELDUQUE, MARQUES, CIARLINI, 2013, p. 183).

A presente pesquisa se justifica na medida em que a intervenção do Poder Judiciário nas políticas de saúde pode ser prejudicial à população que necessita do Sistema Único de Saúde (SUS) para sua sobrevivência, uma vez que o orçamento público é limitado.

Para Daniel Wang:

\begin{abstract}
Além do mais, é preciso olhar não só para quem ganha, mas também para quem perde com determinada forma de alocar recursos. Não é irrazoável afirmar que a grande quantidade de recursos da saúde gasta para cumprir as decisões judiciais não pode ser alocada sem afetar outras políticas de saúde que, por sua vez, também protegem o que seria o mínimo existencial de outros cidadãos (2014, p. 308-318.)
\end{abstract}

O presente artigo tem como objetivo trazer à discussão uma análise histórica, atual e perspectivas acerca da judicialização da saúde. Como objetivo específico pretende-se compreender as causas da judicialização, conhecer o panorama atual, analisar estatísticas, coletar decisões judiciais e buscar alternativas para sua redução no futuro. Utiliza método de pesquisa integrativo, indutivo, pesquisa jurisprudencial e de dados.

\title{
2. Contexto Histórico
}

Montesquieu, valendo-se do legado de seu antecessor britânico John Locke e do filosofo grego Aristóteles, abordou a reformulação das instituições políticas com base na teoria dos três poderes. A divisão das funções do Estado em três poderia ser a saída para corrigir as ações ditatoriais praticadas pelos absolutistas.

Quando se referiu à República, Montesquieu (1996, p. 32) esclareceu que “o governo é exercido diretamente pelo povo, que define os rumos políticos por meio de participação direta dos cidadãos". A par destes e de outros conceitos sobre as formas de governo, o filósofo iniciou sua importante contribuição para os Estados na medida em que demonstrava as funções reais e inconfundíveis dos poderes, construindo suas conclusões no sentido de que estas funções fossem entregues a um só órgão (Estado). Entretanto, que as mesmas fossem separadas em três, com suas finalidades. Montesquieu (1996) considerava as Repúblicas fracas, porque dependiam das virtudes dos cidadãos. Ou seja, para que as Repúblicas existissem seriam necessários que os cidadãos se dispusessem a colocar o 
interesse público acima do particular. Como isso dificilmente ocorre, pois as paixões humanas quase sempre prevalecem sobre a razão, as Repúblicas apresentam uma forte tendência em direção ao absolutismo.

Pois bem, o pensador, sugerindo a divisão do Estado em três poderes, aponta que cada um deles deveria se equilibrar entre a autonomia e a intervenção em relação aos demais, de forma que se respeitassem, coibindo entre si qualquer interferência desarmônica. Portanto, o equilíbrio e a moderação entre os poderes seria a fórmula para estabilidade política.

Para a harmonia entre si, Montesquieu (1996) criou o conceito de equipotência de Poderes, que denota a capacidade de controle mútuo entre executivo, legislativo e judiciário. O Poder Executivo seria exercido pelo rei, que assumiria as responsabilidades pela direção política e administrativa do Estado. Ao legislativo caberia expressar os anseios dos súditos junto à coroa. Ambos os poderes funcionariam como freios e contrapesos, para que nenhum dos lados excedesse suas prerrogativas. Ao judiciário incumbiria o papel de intérprete da lei. A obediência das convicções pessoais dos juízes às leis seria uma das garantias de estabilidade política. Além disso, a decisão jurídica poderia ser sempre previsível, partindo-se do conhecimento das leis.

A partir do momento em que as funções estatais estivessem devidamente diferenciadas, com poderes assegurando a soberania popular e protegendo os direitos fundamentais, tornar-se-ia mais simples o funcionamento da engrenagem estatal: Executivo e legislativo efetivando suas funções inerentes, com o judiciário aplicando as leis nos demais casos, tudo estaria resolvido.

Demais disso, tratando-se de países da América Latina, mormente ao Brasil, verifica-se que foram colônias Portugal ou pela Espanha. Suas independências ocorreram próximas. O Paraguai e a Venezuela (1811), a Argentina (1816), o Chile (1818), a Colômbia (1819), a Costa Rica, El Salvador, a Guatemala, Honduras, o México, o Panamá e o Peru (todos em 1821), o Brasil e o Equador (1822), a Bolívia (1825) e o Uruguai (1826). São nações que saíram de um modelo de gestão estatal colonial para o modelo republicano liberal e, com a sua adoção, ainda que muitas vezes precária, o ideal do Estado Democrático de Direito foi sendo difundido e consolidado no continente (GALO, 2009). 
Contudo, o desenvolvimento do Estado nos países centrais deu-se de forma diversa dos países periféricos ou semi-periféricos. Enquanto o Estado constitucional moderno europeu e anglo-saxão assistiu à emergência e sucessão de períodos de gestão governamental estatal de cunho liberal, de bem-estar social (welfare state ou Estado-providência) e de crise do Estado de bem-estar social, em um período de aproximadamente cento e cinqüenta anos os países latino-americanos vivenciaram longos períodos ditatoriais e, portanto, antidemocráticos (SANTOS; MARQUES; PEDROSO, 1996).

Ainda em fase de construção, a democracia não se sedimentou no Brasil devido ao período do Regime Militar, iniciado em maio de 1964. Foi um período em que as liberdades individuais foram tolhidas e, especificamente o Poder Judiciário, tornou-se dependente e enfraquecido, visto que, por um longo período, o mesmo esteve politicamente neutralizado (SANTOS; MARQUES; PEDROSO, 1996).

Com o fim da ditadura militar e com o advento da Constituição Federal de 1988, voltou a se falar na conquista das liberdades individuais, inclusive previstas no artigo $5^{\circ}$ ao 17 da referida norma. Desacreditada nos Poderes Legislativo e Executivo, a população passou a buscar resposta às suas necessidades no Poder Judiciário, surgindo uma crescente judicialização.

Boaventura de Sousa Santos (2003, p.02) conceitua a judicialização da política defendendo que é possível verificar "sempre que os tribunais, no desempenho normal das suas funções, afetam de modo significativo as condições da acção política"

Quando isso ocorre, a democracia fica fragilizada, sendo inclusive temerosa a possibilidade de colapso no que se refere à harmonia e independência entre os poderes. Em casos recentes, a Suprema Corte brasileira foi chamada a se manifestar em assuntos de relevantes impactos políticos, ou ainda de caráter eminentemente político: suspendeu e ditou o rito do impedimento da então presidente Dilma Roussef. Inclusive, a abertura do processo e seus desdobramentos provocou um quadro no qual a Suprema corte foi compelida a mediar conflitos que não foram resolvidos em seu local próprio; interveio na posse de ministro de Estado indicado pela presidente da República, decidindo pela suspensão do ato administrativo que deu posse; decidiu que a Câmara dos Deputados deveria receber denúncia contra o vice chefe do executivo. Casos dessa temática colocam o 
STF nos holofotes políticos. Entretanto, essa posição privilegiada na resolução das demandas reflete diretamente na (des) harmonia e independência dos poderes.

Nesse quadro preocupante de choque entre os poderes, duas decisões interferiram bruscamente em atos constitucionalmente previstos para presidente do executivo e da câmara, privativamente: Em março de 2016, o ministro Gilmar Mendes concedeu cautelar em mandado de segurança para suspender a posse do ministro da Casa Civil.

Acertadas as palavras de Schmitt (2003, p.43), que repreende:

Quando a política se subordina às ligações jurídicas, perde a qualidade de autentica democracia, numa estrutura de divisão de poderes onde instituições e procedimentos controlam-se e equilibram-se mutuamente.

A judicialização é benéfica, desde que amplie os cânones liberais do direito (COUSO); ou, ela é benfazeja, desde que mantida sob controle popular (YEPES, 2007); ou (b) a judicialização é negativa porque expropria o espaço real da política, diminuindo a possibilidade de autogoverno e a democracia (HIRSCHL, 2004).

\section{Panorama Atual}

A Constituição de 1988 concretizou a universalidade da saúde preconizando ser direito de todos e dever do Estado, garantido mediantes políticas sociais e econômicas que visem à redução do risco de doença e de outros agravos e ao acesso universal e igualitário às ações e serviços para a sua promoção, proteção e recuperação (art. 196 da Constituição).

A Integralidade está descrita no art. 198, inciso II da Constituição Federal que estabelece que as ações e serviços públicos de saúde integram uma rede regionalizada e hierarquizada e constituem um sistema único, organizado a atender integralmente, com prioridade as atividades preventivas, sem prejuízo dos serviços assistenciais.

No que pertine às normas infraconstitucionais, para atender aos ditames constitucionais, foi implementado o Sistema Único de Saúde (SUS) por meio da Lei Orgânica da Saúde (Lei 8.080/90), que especifica seus objetivos, suas atribuições e organização (PAIM et al., 2011).

$\mathrm{O}$ art. $5^{\circ}$ da lei 8.080/90 estabelece os objetivos do SUS, tais como a identificação e divulgação dos fatores condicionantes e determinantes da saúde, a formulação de política de 
saúde destinada a promover, nos campos econômico e social, a assistência às pessoas por intermédio de ações de promoção, proteção e recuperação da saúde, com a realização integrada das ações assistenciais e das atividades preventivas (MENDES, 2013, p. 132).

$\mathrm{O}$ art. $7^{\circ}$, inciso II da mencionada lei conceitua a integralidade em todas as ações e níveis de complexidades do sistema definindo-a como um conjunto articulado e contínuo das ações e serviços preventivos e curativos, individuais e coletivos, exigidos para cada caso em todos os níveis de complexidade do sistema.

Em 1998 foi implementada a Política Nacional de Medicamentos (PNM), instrumentalizada na Portaria n. 3.916/98, do Ministério da Saúde, com o propósito de garantir segurança, eficácia e qualidade dos produtos; a promoção do uso racional; e o acesso da população àqueles medicamentos considerados essenciais (BRASIL, 1998).

A racionalidade é o processo que compreende a prescrição apropriada, a disponibilidade oportuna e a preços acessíveis, a dispensação em condições adequadas e o consumo nas doses indicadas, nos intervalos definidos e no período de tempo indicado de medicamentos eficazes, seguros e de qualidade. Já os medicamentos essenciais são aqueles destinados a atender às necessidades de saúde comuns e prioritárias da população (OMS, 2002).

Em 2004 foi elaborada a Política Nacional de Assistência Farmacêutica (PNAF), através da Resolução n. 338, do Ministério da Saúde, objetivando políticas de medicamentos, ciência e tecnologia, desenvolvimento industrial e formação de recursos humanos (BRASIL, 2004).

A própria resolução conceitua a assistência farmacêutica como um conjunto de ações voltadas à promoção, proteção e recuperação da saúde, individual ou coletivamente, tendo o medicamento como insumo essencial, visando ao acesso e ao seu uso racional (BRASIL, 2004).

Em 2011 foi editado o Decreto n. 7.508/2011 que determina a elaboração de uma lista que contemple os produtos necessários ao tratamento e controle da maioria das patologias da população, respeitadas as diferenças regionais. A cada ano há uma atualização dos medicamentos com a finalidade de atingir a segurança, a eficácia terapêutica, a qualidade e a disponibilidade dos produtos. A responsabilidade da atualização é dos órgãos do Ministério da Saúde, auxiliados por gestores estaduais e municipais, além das instituições 
científicas que atuam na área farmacêutica. Chama-se Relação Nacional de Medicamentos Essenciais (RENAME) quando elaborada pela a União.

Sobre a RENAME, dispõe o Decreto n. 7.508/2011:

Art. 25. A Relação Nacional de Medicamentos Essenciais - RENAME compreende a seleção e a padronização de medicamentos indicados para atendimento de doenças ou de agravos no âmbito do SUS.

Parágrafo único. A RENAME será acompanhada do Formulário Terapêutico Nacional FTN que subsidiará a prescrição, a dispensação e o uso dos seus medicamentos.

Art. 26. O Ministério da Saúde é o órgão competente para dispor sobre a RENAME e os Protocolos Clínicos e Diretrizes Terapêuticas em âmbito nacional, observadas as diretrizes pactuadas pela CIT.

A Portaria MS/GM n. 533, de 28 de março de 2012, estabeleceu o elenco de medicamentos e insumos da Relação Nacional de Medicamentos Essenciais RENAME/2012. Foi estruturada através da Resolução n 1/CIT, de 17 de janeiro de 2012 e contemplava com 810 itens. A RENAME atualizada para o ano de 2018, deliberada pela Resolução CIT nº 25/2017, contempla 1098 medicamentos, totalizando um acréscimo de $26 \%$ em relação ao ano anterior.

As referidas modificações na RENAME é atribuição da Comissão Nacional de Incorporação de Tecnologia - CONITEC, através de processo administrativo instaurado para esse fim. Pode haver incorporação de novas tecnologias no SUS, elaboração ou alteração de protocolos clínicos e diretrizes terapêuticas, tudo realizado pela CONITEC, conforme previsto na Lei $\mathrm{n}^{\mathrm{o}}$ 12.401/2011. Esta lei foi regulamentada pelo Decreto n. 7.646/2011 que, por sua vez, se referiu à CONITEC:

Art. $4^{\circ}$ À CONITEC compete:

I - emitir relatório sobre:

a) a incorporação, exclusão ou alteração pelo SUS de tecnologias em saúde; e

b) a constituição ou alteração de protocolos clínicos e diretrizes terapêuticas; e

II - propor a atualização da Relação Nacional de Medicamentos Essenciais - RENAME nos termos do art. 25 do Decreto no 7.508, de 28 de junho de 2011.

A CONITEC poderá solicitar às unidades do Ministério da Saúde a elaboração de proposta de constituição ou de alteração de protocolos clínicos e diretrizes terapêuticas de interesse para o SUS e deliberar pela incorporação do medicamento, outros passos são necessários. Dentre eles há a programação de medicamentos, que objetiva garantir a 
disponibilidade do produto na quantidade e tempo adequados para atender as necessidades dos cidadãos.

Em seguida deve-se proceder à aquisição dos medicamentos. Este é o momento que os profissionais da saúde dão lugar para outras áreas atuarem, tais como comissão de licitação, departamentos financeiros e de logística. Por fỉm, necessária a organização do transporte, armazenamento e distribuição de medicamentos. Tal medida garante a preservação dos produtos, uma vez que cada produto contém especificidades, tal como acondicionamento a temperatura adequada. Por fim, há a dispensação dos medicamentos, correspondendo à entrega nas mãos do paciente com as orientações de utilização dadas pelo profissional competente.

Em 2004 foi instituído o Programa Farmácia Popular do Brasil (PFPB) que prevê venda de medicamento subsidiada sob três perspectivas: (a) a Rede Própria, onde os cidadãos pagam por um custo aproximado em $10 \%$ do preço do medicamento vendido em farmácia; (b) Aqui Tem Farmácia Popular (2006), através de convênios com farmácias na venda de remédios para controle de hipertensão e diabetes; (c) e o programa Saúde Não Tem Preço (2011), que fornece medicamentos para hipertensão arterial e diabetes mellitus em locais conveniados (BERMUDEZ; OLIVEIRA; LUIZA, 2012).

Em 2006, a Portaria n. 2.577/GM designou que o tratamento à distribuição de medicamentos se dá pela elaboração do Componente de Medicamentos de Dispensação Excepcional (CMDE), a ser executada pelos Estados Federados. Os Estados deverão contemplar situação relacionada à doença rara ou de baixa prevalência, com indicação de uso de medicamento de alto valor unitário ou que, em caso de uso crônico ou prolongado, seja um tratamento de custo elevado; e doença prevalente, com uso de medicamento de alto custo unitário ou que, em caso de uso crônico ou prolongado, seja um tratamento de custo elevado desde que haja tratamento previsto para o agravo no nível da atenção básica, ao qual o paciente apresentou necessariamente intolerância, refratariedade ou evolução para quadro (BRASIL, 2006).

Em 2013, foi editada a Portaria n. 1.554/GM (BRASIL, 2013a) que acrescentou outra atribuição estadual: o fornecimento dos medicamentos classificados como de alto custo, que fazem parte do Componente Especializado de Assistência Farmacêutica. No Estado de Goiás, é realizado pela Central de Medicamentos de Alto Custo Juarez Barbosa (CEMAC). 
Na CEMAC, são dispensados 115 medicamentos em 179 apresentações farmacêuticas para o tratamento de 84 doenças que fazem parte do Componente Especializado da Assistência Farmacêutica (CEAF). Os medicamentos listados no CEAF são dispensados após critérios de diagnóstico, indicação e tratamento, esquemas terapêuticos e demais parâmetros contidos nos Protocolos Clínicos e Diretrizes Terapêuticas do Ministério da Saúde (GOIÁS, 2018).

Em 2010, o CNJ publicou a Recomendação n. 31 que, considerando o volume processual de centenas de milhares de processos em saúde, teve como objetivo orientar os tribunais na adoção de medidas que auxiliem os magistrados para assegurar maior eficiência na solução das demandas judiciais envolvendo a assistência à saúde pública (BRASIL, 2010a).

Naquele ano, o CNJ publicou a Resolução n. 107, que instituiu o Fórum Nacional do Judiciário (FNJ) para monitoramento e resolução das demandas de assistência à saúde. Entre suas atribuições, o FNJ tem a função de elaborar estudos e propor medidas concretas para o aperfeiçoamento, reforço e efetividade dos processos judiciais, além de refletir sobre a prevenção de novos conflitos em matéria de saúde. A Resolução ainda prevê a possibilidade de os tribunais realizarem termos de cooperação técnica com órgãos ou entidades públicas ou privadas para o cumprimento de suas atribuições (BRASIL, 2010b).

Em âmbito municipal, a listagem de medicamentos fornecidos pelos municípios teve origem a partir da Portaria $n^{\circ} 4.217 / G M$, de 29 de dezembro de 2010, que aprovou as normas de financiamento e execução do Componente Básico da Assistência Farmacêutica. Tais componentes devem constar da Relação Municipal de Medicamentos Essenciais (REMUME), com base na RENAME, a partir das necessidades decorrentes do perfil nosológico da população (BRASIL, 2001).

Em 2017 foi editada a Portaria de Consolidação no 2, de 28 de setembro de 2017, que adotou Políticas Gerais de Promoção, Proteção e Recuperação da Saúde, nos seguintes termos:

Art. $2^{\circ}$ São políticas gerais de promoção, proteção e recuperação da Saúde

I - Política Nacional de Promoção da Saúde (PNPS);

II - Política Nacional de Vigilância em Saúde;

III - Política Nacional de Sangue, Componentes e Hemoderivados, instituída pela Lei $\mathrm{n}^{\mathrm{o}}$ 10.205, de 21 de março de 2001;

IV - Política de Saúde Mental, instituída pela Lei no 10.216, de 6 de abril de 2001, na forma do Anexo II;

V - Política Nacional de Alimentação e Nutrição (PNAN), na forma do Anexo III;

VI - Política Nacional de Plantas Medicinais e Fitoterápicos, instituída pelo Decreto ${ }^{\circ}$ 5.813, de 22 de junho de 2006, na forma do Anexo IV; 
VII - Política Nacional de Educação Popular em Saúde (PNEPS-SUS), na forma do Anexo V.

Todas as sete políticas elencadas pelo artigo $2^{\circ}$ da Portaria $n^{\circ} 2$ já existiam. O que ocorreu é que foram agrupadas em portarias consolidadas por tema com o intuito de facilitar a busca, a leitura e o entendimento das referidas normas.

Entretanto, embora existam as diferentes normas acerca da saúde, a Judicialização da Política e, especificamente da saúde, tem tomado proporções insustentáveis. Em 2011 foram contabilizadas 240.980 processos judiciais relacionadas à saúde. Em 2014 392.921. Em 2015, 854.506 (BRASIL, 2017). Entre 2008 e 2015, o gasto do Estado brasileiro para prestar serviços ligados à área da saúde em cumprimento a decisões judiciais cresceu $1.300 \%$, de $\mathrm{R} \$$ 70 milhões para R\$ 1 bilhão só em medicamentos (BRASIL, 2017).

A banalização das demandas em saúde chegou ao ponto de haver pedido de remédio de alto custo para uma cadela, a Jully, por sofre de anemia hemolítica, doença autoimune em que o organismo destrói glóbulos vermelhos protocolizado na $1^{\text {a }}$ Vara da Fazenda Pública Estadual de São Paulo. A liminar foi negada, mas o gasto judicial para a tramitação do processo, além do gasto com servidores e com Procuradores do Estado são prejuízos que deveriam ser considerados (COLLUCI, 2016).

Nessa lógica, para Mazza (2013, p. 136), “as decisões judicias ao não observarem as regras orçamentárias podem colocar em risco todo o planejamento já definido para a realização das políticas de saúde, além de inviabilizar a realização destas". O que depreende se é que o judiciário encontre parâmetros para controlar, de forma justa e eficiente, o controle do fenômeno da judicialização da saúde no Brasil.

David; Andrelino; Beghin (2016, p. 25) complementam:

Como os gastos com a judicialização de medicamentos não constam nem nos planos anuais de saúde nem nas Leis Orçamentárias Anuais (LOA), seu pagamento deve ser efetuado retirando-se recursos dos componentes existentes. Por intermédio dos Relatórios Anuais de Gestão (RAG), foi observado que geralmente isso ocorre por meio da Ação 4705 (Ceaf - Componente Especializado da Assistência Farmacêutica) do Plano Plurianual (PPA). Isso se reflete no aumento exponencial dos gastos com o componente Ceaf, uma vez que, se fosse excluída a judicialização, não haveria necessidade de ampliar tanto o orçamento desse componente, por não existir uma variação tão grande do número de pacientes portadores das doenças que esse componente atende, como é o caso de doenças raras, artrite reumatóide e alguns casos de hepatites. 
O cenário atual é fruto de uma credibilidade exacerbada que Poder Judiciário tem sobre a opinião pública. Entretanto, não é este o melhor caminho, visto que política pública é atribuição dos Poderes Legislativo e Executivo. O juiz não tem legitimidade para implantar política pública porque não foi eleito pelo voto. Sob essa perspectiva, tem-se uma democracia fragilizada.

\section{Perspectivas Futuras}

Consenso entre os pesquisadores é que a judicialização das políticas de saúde não pode continuar sob pena de inviabilização da proposta do Sistema Único de Saúde (SUS).

Em 2010, o CNJ publicou a Recomendação n. 31 que, considerando o volume processual de centenas de milhares de processos em saúde, teve como objetivo orientar os tribunais na adoção de medidas que auxiliem os magistrados para assegurar maior eficiência na solução das demandas judiciais envolvendo a assistência à saúde pública (BRASIL, 2010a).

Naquele ano, o CNJ publicou a Resolução n. 107, que instituiu o Fórum Nacional do Judiciário (FNJ) para monitoramento e resolução das demandas de assistência à saúde. Entre suas atribuições, o FNJ tem a função de elaborar estudos e propor medidas concretas para o aperfeiçoamento, reforço e efetividade dos processos judiciais, além de refletir sobre a prevenção de novos conflitos em matéria de saúde. A Resolução ainda prevê a possibilidade de os tribunais realizarem termos de cooperação técnica com órgãos ou entidades públicas ou privadas para o cumprimento de suas atribuições (BRASIL, 2010b).

A autocomposição pode significar uma redução na judicialização porque antecipa a fase judicial por meio de acordos entre as partes. A resolução do litígio se dá por obra dos próprios litigantes que exige uma expressão altruísta, pois deriva de atitude de renúncia ou reconhecimento a favor do adversário.

$\mathrm{Na}$ solução pela autocomposição, são três as suas formas tradicionais, quais sejam, renúncia ou desistência por parte de quem deduz a pretensão, submissão ou reconhecimento de quem se opõe à pretensão ou transação, através de concessões recíprocas.

Bastante elucidativo é o conceito formulado por Didier (2014, p. 209): 
Mediação e conciliação são formas de solução de conflito pelas quais um terceiro intervém em um processo negocial, com a função de auxiliar as partes a chegar à autocomposição. (...) Não são, por isso, espécie de heterocomposição do conflito; trata-se de exemplos de autocomposição, com a participação de um terceiro.

No tocante à diferença entre as técnicas, o comportamento do terceiro interventor é que se servira de norte para desvencilhar da tênue linha que separa os institutos. No caso da conciliação, o terceiro, que será denominado conciliador, tem participação ativa, podendo, inclusive, apontar soluções para o conflito das partes. Diversamente, o terceiro elencado na mediação - o mediador - servirá de facilitador, identificando interesses, pontos em comum e fazendo o diálogo fluir, não podendo, em nenhuma hipótese, apontar solução para dirimir o conflito. Ressalta-se que o terceiro não pode compelir as partes a transigirem.

Outro ponto que diferencia as técnicas diz respeito a sua recomendação. Enquanto a mediação é indicada para os casos em que exista vínculo preexistente entre as partes, a conciliação é indicada para os casos nos quais haja inexistência de qualquer proximidade anterior, fundamentando-se, para tanto, o próprio papel do terceiro nas duas técnicas, que podem ocorrer judicialmente (no curso de um processo judicial) ou extrajudicialmente (antes mesmo da propositura de uma ação judicial).

No Brasil, os marcos regulatórios que disciplinam os métodos consensuais são três: (a) a Resolução n. 125/201022, do Conselho Nacional de Justiça (CNJ); (b) a Lei n. 13.105/201523 (Código de Processo Civil); e (c) a Lei n. 13.140/201524, que trata da mediação.

O Tribunal de Justiça do Estado de Goiás foi instituída a Câmara de Saúde do Judiciário, materializada no Termo de Cooperação Técnica $n^{\circ}$ 001/2012, que hoje é denominada de Núcleo de Apoio Técnico do Judiciário (Natjus). A função do Natjus é fornecer ao julgador informações suficientes para auxiliá-lo em suas decisões.

Há uma tendência de que os diversos tribunais dediquem varas exclusivas para julgarem demandas de saúde. Tais iniciativas tornam juízes especialistas no assunto, o que é louvável em face da ausência obrigatoriedade da disciplina Direito Sanitário das grades curriculares das faculdades de direito e ausência nos editais para provimento de vagas para juízes, promotores, defensores públicos e procuradores públicos. Na Comarca de Goiânia, desde 2018, cabe à $2^{\mathrm{a}}$ Vara da Fazenda Pública Estadual e $2^{\mathrm{a}}$ Vara da Fazenda Pública Municipal de Goiânia julgamentos afetos à saúde e medicamentos. Nesta mesma esteira, foi instalado em 2019 o Centro Judiciário de Soluções de Conflito e Cidadania da Saúde - 
CEJUSC da Saúde. Trata-se de unidade do Poder Judiciário, vinculada ao Núcleo Permanente de Métodos Consensuais de Solução de Conflitos (NUPEMEC), órgão de assessoramento da Presidência do Tribunal de Justiça do Estado de Goiás-TJ/GO. O objetivo principal do CEJUSC é utilizar métodos consensuais de soluções de disputas, assegurando à sociedade um serviço de tratamento dos conflitos de saúde de forma acessível, ágil, eficaz e efetiva, garantindo o direito de acesso à soluções justas e à cidadania.

Romério do Carmo Cordeiro (CNJ, 2019), coordenador do programa justifica a participação do Poder Judiciário nesta seara:

\begin{abstract}
Se de um lado as políticas públicas normatizadas representam importantes garantias jurídicas na proteção do direito à saúde, a possibilidade de intervenção do Poder Judiciário na efetivação do direito à saúde representa a última garantia de um cidadão ou de uma coletividade contra uma eventual violação ou ameaça ao direito à saúde. Compete ao Nupemec o desenvolvimento de política judiciária de tratamento adequado dos conflitos de interesses. Por isso, o Cejusc da Saúde terá uma função estratégica no sentido de aproximar ao máximo a capacidade da necessidade, oferecendo um ambiente propício que estimula o diálogo e a interação, antes de aplicar a decisão judicial.
\end{abstract}

Há ainda os Conselhos Estaduais de Saúde, que atuam na formulação de estratégias e no controle da execução das políticas de saúde, atribuições estas que são também do próprio Poder Executivo e do Poder Legislativo.

\title{
5 Considerações Finais
}

Em um cenário de evolução tecnológica crescente, onde a saúde constitui um direito do cidadão e um dever do Estado, pedidos via judicial que demandam por medicamentos se multiplicaram, gerando a necessidade de discussões em torno dos aspectos técnicos, econômicos, sociais e jurídicos que permeiam o tema, a fim de subsidiar a tomada de decisões.

Cada Poder da Federação tenta fazer a sua parte na tentativa de dirimir as demandas da saúde. O Poder Legislativo aprovando novas normas, o Poder Executivo destinando orçamento, buscando convênios e criando políticas públicas e o Poder Judiciário determinando individualmente o fornecimento de medicamentos e demais tratamentos de saúde.

O Poder Judiciário, órgão cuja função precípua é concretizar a justiça nas demandas ajuizadas, muitas vezes não tem condições de, ao examinar determinada pretensão à prestação 
de um direito social, analisar as consequências globais da destinação de recursos públicos em benefício de demanda individual, com invariável prejuízo para o todo. Além disso, o juiz está preparado para julgar casos concretos individuais, o que fatalmente resultaria em prejuízo à coletividade.

A autocomposição, os conselhos de saúde e as câmaras técnicas precisam ser reconhecidos como verdadeiros mecanismos capazes de proporcionar uma justa distribuição de saúde no Brasil.

É necessário um esforço de todos para a solução das demandas da saúde, sejam defensores públicos, promotores de justiça, juízes e até médicos, de maneira a buscar e encontrar as respostas necessárias para solução dos litígios a fim de que a Constituição Federal de 1988 seja cumprida, com o atendimento integral no que tange à saúde.

\section{Referências}

BRASIL . CONSELHO NACIONAL DE JUSTIÇA. Resolução n. 107, de 28 de junho de

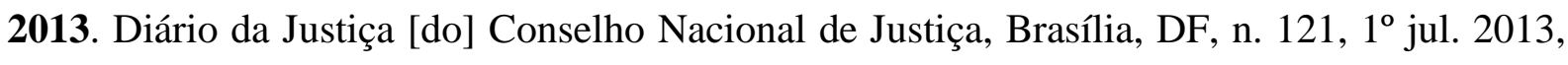
p. 2-3. Disponível em: <https://hdl.handle.net/20.500.12178/30979>.

. Conselho Nacional de Justiça. Recomendação $\mathbf{n}^{\mathbf{0}}$ 31, de 30 de março de 2010. Diário da Justiça 61/2010, em 07/04/2010, p. 4-6. Disponível em: <http://www.cnj.jus.br/atos-administrativos/atos-da-presidencia/322-recomendacoes-doconselho/12113-recomendacao-no-31-de-30-de-marco-de-2010>. Acesso em: 20 ago. 2017.

Conselho Nacional de Justiça. Tribunal inaugura Cejusc exclusivo para demandas de saúde. Notícias do Judiciário, em 25/09/2019, p. 4-6. Disponível em: <https://www.cnj.jus.br/tribunal-inaugura-cejusc-exclusivo-para-demandas-de-saude/>. Acesso em: 12 abr. 2020. 
TRIBUNAL DE CONTAS DA UNIÃO. Notícia em 23/08/2017. Aumentam os gastos públicos com judicialização da saúde. https://portal.tcu.gov.br/imprensa/noticias/aumentam-os-gastos-publicos-com-judicializacaoda-saude.htm

COLLUCI, Claudia, Família pede na Justiça que SUS dê remédio de alto custo para cadela. Folha de São Paulo, 07/09/2016. Cotidiano, p.B-2

COUSO, Javier A. The politics of judicial review in Chile in the era of democratic transition, 1990-2002. Democratization, [S. 1.]: Routledge, v. 10, n. 4, p. 70-91, 2003.

DAVID, G.; ANDRELINO, A.; BEGHIN, N. Direito a medicamentos - Avaliação das despesas com medicamentos no âmbito federal do sistema único de saúde entre 2008 e 2015. 2016. Disponível em: <http://www.inesc.org.br/biblioteca/publicacoes/textos/direitoamedicamentos-avaliacao-das-despesas-com-medicamentos-no-ambito-federal-dosistemaunico-de-saude-entre-2008-e-2015/view>. . Acesso em 12 jan. 2017.

DECLARAÇÃO UNIVERSAL DOS DIREITOS HUMANOS. Assembleia Geral das Nações $\begin{array}{lllll}\text { Unidas } & \text { em } & \text { Paris. } & 10 & \text { dez. }\end{array}$ <http://www.dudh.org.br/wpcontent/uploads/2014/12/dudh.pdf>. Disponível em: . Acesso em: 26 jun. 2018.

DIDIER, Fredie. Curso de Direito Processual Civil, Volume 1. 16.ed. Salvador: Juspodvm, 2014. 620p.

HIRSCHL, Ran. Towards juristocracy: The origins and consequences of the new constitutionalism. First Harvard University Press, 2004

MAZZA, F. F. Os impasses entre a judicialização da saúde e o processo orçamentário sob a responsabilidade fiscal: uma análise dos fundamentos decisórios do Supremo Tribunal Federal. Dissertação (Mestrado em Saúde Pública) - Universidade de São Paulo. São Paulo, 2013.

MONTESQUIEU, Charles de Secondat, Baron de. O Espírito das Leis: as formas de governo, a federação, a divisão dos poderes, presidencialismo versus parlamentarismo; introdução, tradução e notas de Pedro Vieira Mota. - $4^{\mathrm{a}}$ ed. melhor. - São Paulo: Saraiva, 1996.

Rev. de Direitos Sociais, Seguridade e Previdência Social | e-ISSN: 2525-9865 | Evento Virtual | v. 6 | n. 1 | p. 1-17 | Jan/Jun. 2020 
SANTOS, Boaventura de Sousa. A judicialização da política. 2003. Disponível em: <http://www.ces.uc.pt/opiniao/bss/078en.php> . Acesso em 04 de julho de 2018.

SANTOS, Boaventura de Sousa; MARQUES, Maria Manuel Leitão; PEDROSO, João. Os tribunais nas sociedades contemporâneas. Revista Brasileira de Ciências Sociais, ano 11, n. 30, p. 29-62, fev. 1996.

SCHMITT, Carl. Teoría de La Constitución. Presentación de Francisco Ayala. Primera edición em “Alianza Universidad Textos” 1982. Cuarta reimpresión em “Alianza Universidad Textos”. Madrid. España. 2003.

YEPES, Rodrigo Uprimmy. The enforcement of social rights by the Colombian Constitutional Court: cases and debates. In: GARGARELLA, Roberto; DOMINGO, Pilar; ROUX, Theunis (Ed.). Courts and social transformation in new democracies: an institutional voice for the poor? London: Ashgate, 2006. p. 153-168; Cf. também YEPES, Rodrigo Uprimmy. Judicialization of politics in Colombia: cases, merits, and risks. Sur: international journal on human rights, São Paulo: Human Rights University Network, n. 6, p. 49-65, 2007.

WANG, Daniel Wei Liang. Constituição e política na democracia (Aproximação entre direito e ciência política).São Paulo:Marcal Pons, 2014.

VERbiCARO, L., \& Santos, A. (2017). A Necessidade De Parâmetros Para A Efetivação Do Direito À Saúde: A Judicialização Do Acesso Ao Hormônio Do Crescimento No Estado Do Pará. Revista De Direito Sanitário, 17(3), 185-211. Https://Doi.Org/10.11606/Issn.2316-9044.V17i3p185-211 